\title{
O grau de INFORMATIZAÇÃO DOS SISTEMAS de gestão da produção DAS GRANDES EMPRESAS industriais no Brasil
}

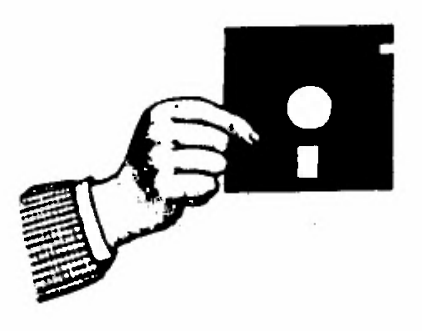

- JAIME EVALDO FENSTERSEIFER

Professor do Programa de Pós-Graduaçāo em Administraçāo e do Departamento de Ciências Administrativas da Universidade Federal do Rio Grande do Sul.

\section{- RICARDo melo bastos}

Mestrando do Programa de Pós-Graduação em Administração da Universidade Federal do Rio Grande do Sul e Professor do Instituto de Informática da Pontificia Universidade Católica do Rio Grande do Sul.

\section{INTRODUÇÃO}

\begin{abstract}
A s novas tecnologias de produção, tanto geA renciais como de processo, decorrentes principalmente do uso da informática, trouxeram como conseqüência uma renovada importância à função de produção das empresas industriais. Essas inovações técnicas e gerenciais modificam profundamente a gestão da produção, que assume, mais do que nunca, um caráter estratégico. Elas oferecem aos administradores industriais uma vasta gama de alternativas para melhorarem a produtividade de suas
\end{abstract}

empresas bem como para obterem outros tipos de vantagens competitivas.

Até que ponto essa verdadeira revolução da produção, que vem ocorrendo nos países desenvolvidos, está se refletindo no comportamento das empresas industriais no Brasil? Para responder a essa pergunta, foi realizada uma pesquisa, em 1986, pelo Programa de Pós-Graduação em Administração da UFRGS, visando a coletar informações que permitissem descrever e avaliar o estado-da-arte dos sistemas de gestão da produção das grandes empresas industriais brasileiras $^{(1)}$, no que tange aos seus aspectos estruturais, organizacionais, tecnológicos e operacionais.

A pesquisa foi realizada através de um questionário (2), enviado pelo correio ao Gerente de Produção de cada empresa. $O$ questionário foi

1. Empresas atuando no Brasil, independentemente da origem do seu capital.

2. O questionário utilizado nesta pesquisa foi elaborado conjuntamente com o Professor Bernard Ballaz, da Universidade de Grenoble, no âmbito do convênio CAPES-COFECUB, e foi aplicado, simultaneamente, na França. Uma análise comparativa BrasilFrança será objeto de um estudo posterior. 
estruturado em oito seções, a saber:

1. Características gerais da empresa.

2. Características relativas ao sistema de produção.

3. Descrição do sistema de gestão da produção atual, em implantação ou previsto (horizonte de dois anos):

- planejamento e organização da produção;

- gestão operacional.

4. A gestão dos estoques:

- sistemas de reposição de estoques;

- utilização do computador.

5. A utilização de sistemas computadorizados:

- sistema próprio;

- pacote aplicativo.

6. Avaliação das aplicações realizadas:

- razões que levaram à implantação de um sistema computadorizado de gestão da produção;

- resultados advindos da implantação.

7. As perspectivas futuras de desenvolvimento:

- grau de computadorização previsto;

- utilização de sistemas do tipo MRP e KANBAN

8. Equipamentos de computação disponíveis:

- configuração do sistema computacional;

- manipulação das informações;

- uso de CAD, CAE e CAM;

- existência de máquinas de comando nu- mérico;

- sistemas flexíveis de manufatura (FMS).

Em virtude da amplitude da pesquisa, no presente artigo são abordados apenas os aspectos que envolvem o planejamento da produção, informatização do sistema e subsistemas de gestão da produção, recursos computacionais utilizados e disponiveis, motivos e problemas que levaram à informatização da gestão da produção, resultados advindos das aplicações realizadas e perspectivas futuras de desenvolvimento. Os demais itens serão objeto de um artigo posterior.

\section{DESCRIÇÃO DO UNIVERSO DA PESQUISA E DA AMOSTRA DE TRABALHO}

O universo da pesquisa é composto pelas indústrias de grande porte dos setores $\mathrm{Me}$ talúrgico, Mecânico, de Material Eletrônico e de Material de Transporte. Tais setores foram selecionados tendo-se em vista a diversificação de suas características no que tange ao sistema e processo de fabricação e ao tipo de atividade manufatureira. Outro aspecto considerado na seleção foi a complexidade dos sistemas de planejamento e controle da produção necessários para fornecer suporte às empresas desses setores.

A população alvo da pesquisa consistiu nas 500 maiores empresas do universo acima defi-

QUADRO 1: Amostra: Distribulçáo Setorial e Subsetorial

\begin{tabular}{|c|c|c|c|c|}
\hline Setor & Subsetor & $\begin{array}{c}\text { População } \\
\text { alvo }\end{array}$ & $\begin{array}{c}\text { Amostra de } \\
\text { trabalho }\end{array}$ & $\%$ \\
\hline Metalurgia & $\begin{array}{l}\text { Siderurgia } \\
\text { Metalurgia dos não-ferrosos } \\
\text { Produtos Metalúrgicos diversos }\end{array}$ & $\begin{array}{r}49 \\
31 \\
123\end{array}$ & $\begin{array}{r}17 \\
6 \\
30\end{array}$ & $\begin{array}{l}34,7 \\
19,3 \\
24,4\end{array}$ \\
\hline Mecânica & $\begin{array}{l}\text { Máquinas, motores e equipamentos industriais } \\
\text { (inclusive elétricos) } \\
\text { Máquinas, aparelhos e instrumentos para } \\
\text { escritório }\end{array}$ & $\begin{array}{l}93 \\
22\end{array}$ & $\begin{array}{r}37 \\
9\end{array}$ & $\begin{array}{l}39,8 \\
40,9\end{array}$ \\
\hline $\begin{array}{l}\text { Material } \\
\text { Eletroeletrônico }\end{array}$ & $\begin{array}{l}\text { Material elétrico } \\
\text { Aparelhos domésticos, material de comunicação, } \\
\text { lâmpadas, acessórios e utensílios }\end{array}$ & $\begin{array}{l}36 \\
42\end{array}$ & $\begin{array}{l}15 \\
11\end{array}$ & $\begin{array}{l}41,7 \\
26,2\end{array}$ \\
\hline $\begin{array}{l}\text { Material de } \\
\text { Transporte }\end{array}$ & $\begin{array}{l}\text { Construção naval } \\
\text { Material ferroviário } \\
\text { Veículos automotores } \\
\text { Autopeças e carrocerias } \\
\text { Tratores, máquinas de terraplenagem } \\
\text { e implementos } \\
\text { Avióes e outros veículos }\end{array}$ & $\begin{array}{r}9 \\
8 \\
11 \\
52 \\
18 \\
6\end{array}$ & $\begin{array}{r}4 \\
4 \\
6 \\
13 \\
9 \\
9\end{array}$ & $\begin{array}{l}44,4 \\
50,0 \\
54,5 \\
25,0 \\
50,0 \\
50,0\end{array}$ \\
\hline Total & & 500 & 164 & 32,8 \\
\hline
\end{tabular}


TABELA 1: Caracterizaçăo do Sistema de Fabricaçăo

\begin{tabular}{lrr}
\hline Quanto ao & Freq. Abs. & $\%$ \\
\hline Destino da produção: & & \\
- Fabricação para estoque & 31 & 19,0 \\
- Fabricação por encomenda & 96 & 58,9 \\
- Ambos & 36 & 22,1 \\
$\quad$ Total & 163 & 100,0 \\
\hline
\end{tabular}

Tipo de atividade manufatureira:

- Montagem

- Fabricação própria de componentes

- Ambos

Total

$\begin{array}{rr}25 & 16,4 \\ 69 & 45,4 \\ 58 & 38,2 \\ 152 & 100,0\end{array}$

Processo de fabricação:

- Job-Shop (oficina)

$\begin{array}{rr}46 & 29,7 \\ 27 & 17,4 \\ 7 & 4,5 \\ 75 & 48,4 \\ 155 & 100,0\end{array}$

Processo contínuo

- Linha de montagem

- Combinação de dois ou mais processos Total

Organização do fluxo de produção:

- Por linha de produto

- Por processo

Total

$\begin{array}{rr}56 & 39,7 \\ 85 & 60,3 \\ 141 & 100,0\end{array}$

nido, tomando como variável classificatória o patrimônio líquido dessas empresas, de acordo com o levantamento realizado pela revista VISÃO, Quem é Quem na Economia Brasileira, no ano de 1985. O Quadro 1 apresenta, discriminado por setor e subsetor, o número de empresas componentes da população alvo e da amostra de trabalho (número de respondentes) e o percentual de retorno dos questionários.

Constata-se, no Quadro 1, uma representatividade satisfatória de cada subsetor na amostra de trabalho, com uma taxa global de retorno de questionários de $32,8 \%$, o que permite tirar conclusões válidas sobre os sistemas de gestão da produção da população alvo da pesquisa.

As empresas componentes da amostra de trabalho são, na quase totalidade $(94,5 \%)$, do setor privado; destas, $81,3 \%$ são de capital nacional. Aproximadamente dois terços $(67,7 \%)$ das empresas na amostra fazem parte de grupos empresariais.

\section{ANÁLISE DOS RESULTADOS}

\subsection{Caracterização do Sistema de Fabricação}

A Tabela 1 apresenta alguns elementos que caracterizam o sistema de fabricação das empre- sas consultadas. A maioria das empresas $(58,9 \%)$ adota uma política de fabricação por encomenda, sendo relativamente baixo o percentual $(19 \%)$ referente às que fabricam para estoque. Um percentual de $22,1 \%$ das empresas consultadas foi considerado como adotando ambas as políticas ${ }^{(3)}$.

Quanto ao tipo de atividade manufatureira, há uma ligeira predominância das empresas que se caracterizam pela fabricação própria de componentes em relação às que desempenham uma combinação desta com a atividade de montagem (para o caso de ambas as atividades, montagem e fabricação própria de componentes, representarem mais de $20 \%$ da atividade manufatureira), sendo pequeno $(16,4 \%)$ o número de empresas que se caracterizam somente pela montagem.

Relativamente ao processo de fabricação, praticamente a metade das empresas $(48,4 \%)$ utiliza uma combinação de dois ou mais processos,

3. Considera-se que uma empresa adota ambas as políticas quando o percentual de fabricaçāo realizado tanto para estoque como para encomenda for superior a $20 \%$. 
sendo que existe um percentual significativo $(29,7 \%)$ de usuários de job-shop (oficina).

No que tange à organização do fluxo de produção, existe uma predominância na organização por processo $(60,3 \%)$ em relação à organização por linha de produto $(39,7 \%)$.

\subsection{O Planejamento da Produção}

Conforme se observa na Tabela 2, a parcela de empresas que já possui um plano de produção totalmente computadorizado corresponde a $25 \%$ das empresas respondentes. Mas, somando-se a estas as empresas que estão em fase de implantação de um sistema computadorizado e as que possuem um sistema misto (manual e computadorizado), conclui-se que mais da metade das empresas $(52,5 \%)$ utiliza-se da informática no planejamento da produção. Dado que o horizonte para previsão de implantação da computadorização é até o ano de 1988, as perspectivas indicam que somente $26,2 \%$ das empresas do porte consultado terão seus planos de produção

TABELA 2: Plano de Produçáo - Sistema Utilizado ainda elaborados manualmente.

Procurando caracterizar a estrutura do sistema de gestão da produção, a nível de planejamento (hoje, em implantaçăo e previsto), formulou-se uma questão composta por duas alternativas como resposta, sendo, a primeira, "sistema centralizado dirigido pelo plano de produção", e a segunda, "sistema descentralizado, com autonomia a cada subsistema de gestão". Os resultados são apresentados na Tabela 3 , onde se verifica que a grande maioria das empresas $(80,7 \%)$ possui um sistema centralizado de planejamento da produção e pretende mantê-lo centralizado. Apenas $8,4 \%$ das empresas possuem um sistema descentralizado e desejam mantê-lo assim. As demais empresas $(10,9 \%)$ encontram-se em fase de mudança de sistema ou prevendo tal mudança, sendo que a tendência mais forte para esse grupo de empresas é a passagem do sistema descentralizado para o centralizado $(6,4 \%)$, definindo as grandes empresas brasileiras como caracteristicamente

\begin{tabular}{lrr}
\hline Sistema Utilizado & Freq. Abs. & $\%$ \\
\hline Manual & 42 & 26,2 \\
Computadorizado & 40 & 25,0 \\
Manual/implantando computadorização & 37 & 23,1 \\
Manual/prevista computadorizaçāo & 34 & 21,3 \\
Misto & 7 & 4,4 \\
Total & 160 & 100,0 \\
\hline
\end{tabular}

TABELA 3: Estrutura do Sistema de Gestáo da Produção

\begin{tabular}{lcc}
\hline Sistema & Freq. Abs. & $\%$ \\
\hline Centralizado & 125 & 80,7 \\
Centralizado/implantando descentralizaçāo & 3 & 1,9 \\
Centralizado/prevendo descentralização & 4 & 2,6 \\
Descentralizado & 13 & 8,4 \\
Descentralizado/implantando centralização & 9 & 5,8 \\
Descentralizado/prevendo centralizaçāo & 1 & 0,6 \\
Total & 155 & 100,0 \\
\hline
\end{tabular}

TABELA 4: Participaçáo dos Responsáveis das Demais Funçбes da Empresa no Planejamento da Produçấo

\begin{tabular}{lr}
\hline Funçäo & Percent \\
\hline Marketing & 81,7 \\
Materiais & 93,0 \\
Recursos humanos & 34,4 \\
Finanças & 50,5 \\
Direçăo geral & 81,8
\end{tabular}


TABELA 5: Empresas com Plano Estratégico Formalmente Elaborado

\begin{tabular}{ccr}
\hline Possui Plano Estratégico Formal? & Freq. Abs. & $\%$ \\
\hline Sim & 107 & 66,1 \\
Não & 55 & 33,9 \\
Total & 162 & 100,0 \\
\hline
\end{tabular}

TABELA 6: Participaçáo do Responsável pela Produçáo na Elaboraçáo do Plano Estratéglco

\begin{tabular}{lcc}
\hline Nivel de Participação & Freq. Abs. & $\%$ \\
\hline Não participa & 3 & 2,8 \\
E consultado & 36 & 34,3 \\
Participa ativamente & 66 & 62,9 \\
Total & 105 & 100,0 \\
\hline
\end{tabular}

centralizadas do ponto de vista do planejamento da produção.

Com relação à participação dos responsáveis pelas demais funções da organização no planejamento da produção, observa-se, através dos resultados apresentados na Tabela 4, a existência de uma alta participação da área de Materiais (93\%), Direção Geral $(81,8 \%)$ e Marketing $(81,7 \%)$. Tal quadro demonstra um significativo nivel de interação nas organizações brasileiras, no que tange ao seu planejamento de produção.

Aproximadamente dois terços das empresas da amostra possuem um plano estratégico formalmente elaborado (Tabela 5), no qual, em $62,9 \%$ dessas empresas, o responsável pela produção tem participação efetiva (Tabela 6). É importante destacar que somente $2,8 \%$ das empresas que possuem um plano estratégico formal prescindem da participação do responsável pela produção em sua elaboração, caracterizando a aplicação do conceito de planejamento estratégico em seu sentido mais amplo e abrangente pelos dirigentes das grandes empresas brasileiras.

Finalmente, no que tange ao sistema de acompanhamento e controle (Tabela 7), para $56 \%$ das empresas os indicadores de desempenho (volume, custo, eficácia) utilizados no sistema de gestão da produção fornecem parâmetros que permitem à empresa situar-se em relação à trajetória que conduz aos objetivos estratégicos. Somente $24,8 \%$ das empresas afirmam que seus sistemas ainda apresentam numerosas lacunas, o que demonstra um significativo grau de desenvolvimento em instrumento de controle nas grandes empresas brasileiras.

\subsection{Computadorização do Sistema de Gestão da Produção}

Caracterizado o sistema de produção das empresas consultadas, bem como alguns elementos básicos que definem o planejamento e controle da produção, passamos a analisar os aspectos relativos ao uso da informática na gestão da produção.

Constata-se, através da Tabela 8 , que $36 \%$ das empresas respondentes não fazem uso dos recursos fornecidos pelo processamento eletrônico de dados em seus sistemas de gestão da produção. Referimo-nos às demais empresas (64\%) como sendo "informatizadas", embora em grau diferenciado, como será analisado mais adiante. Os dados mostram ainda que $33,5 \%$ das empresas na amostra (o que representa pouco mais da metade - $52,4 \%$ - das empresas informatizadas) optaram por desenvolver sistema próprio, enquanto as soluções ofereci-

TABELA 7: Indicadores de Desempenho da Gestáo da Produçáo como Instrumentos de Acompanhamento e Controle

\begin{tabular}{lcc}
\hline Situação & Freq. Abs. & $\%$ \\
\hline Permitem situar-se em relação à trajetória que conduz aos objetivos estratégicos & 88 & 56,0 \\
Permitem unicamente o controle interno da função & 36 & 22,9 \\
Ainda apresentam numerosas lacunas & 39 & 24,8 \\
\hline
\end{tabular}

Número de respondentes: 157 
das por um pacote aplicativo foram adotadas por $23,8 \%$ das empresas $(37,1 \%$ das empresas informatizadas), sendo que $6,7 \%$ das empresas (10,5\% das empresas informatizadas) optaram por um sistema misto (parte por um pacote aplicativo, parte por sistema desenvolvido pela própria empresa).

A implantação de um pacote aplicativo normalmente acarreta um trabalho de adaptação. A Tabela 9 demonstra que o trabalho desenvolvido para adaptar o pacote aplicativo foi substancial para aproximadamente a metade das empresas que optaram pela compra de um pacote e muito grande para uma em cada cinco destas, sendo, portanto, expressivo o nivel de ajustes realizados para a implantação desses sistemas.

Segundo os dados levantados, $68,9 \%$ das empresas que optaram por um pacote aplicativo (incluindo as empresas do grupo "ambos" da Tabela 8) consideraram a possibilidade de desenvolver um sistema próprio. A Tabela 10 relaciona os motivos pelos quais tal alternativa foi abandonada, onde se destaca o "tempo de desenvolvimento excessivamente longo", o qual foi apontado por aproximadamente três quartos dessas empresas.

Relativamente às empresas que adotaram a solução de desenvolver um sistema próprio, observa-se, na Tabela 11, que esse sistema foi desenvolvido na grande maioria das empresas $(69,3 \%)$ por um grupo interno de informática, uma solução que permite total autonomia na manutenção e expansão do sistema, no sentido de constantemente adequá-lo às suas necessidades específicas. Apenas uma em cada $10 \mathrm{em}-$ presas teve seus sistemas desenvolvidos unicamente por firma de consultoria.

Pouco menos de dois terços $(63,5 \%)$ das empresas que se decidiram pelo desenvolvimento de um sistema próprio (incluindo as empresas do grupo "ambos" da Tabela 8) consideraram a hipótese de compra de um pacote aplicativo. A Tabela 12 apresenta os motivos pelos quais essas empresas renunciaram a essa alternativa, onde se observa que o motivo mais apontado $(82,5 \%)$ por essas empresas foi a "inadequação às características do seu processo de produção". A dificuldade de integração com os aplicativos já existentes na empresa também teve alto índice de indicação, sendo apontada pela

TABELA 8: Computadorizaçáo da Gestáo da Produçáo - Soluçáo Adotada

\begin{tabular}{lcc}
\hline Solução Adotada & Freq. Abs. & $\%$ \\
\hline Pacote aplicativo & 39 & 23,8 \\
Sistema próprio & 55 & 33,5 \\
Ambos & 11 & 6,7 \\
Não utiliza computador & 59 & 36,0 \\
Total & 164 & 100,0 \\
\hline
\end{tabular}

TABELA 9: Trabalho de Adaptaçáo ao Pacote Aplicativo

\begin{tabular}{lcc}
\hline Nivel & Freq. Abs. & $\%$ \\
\hline Nulo & 1 & 2,3 \\
Pequeno & 11 & 25,0 \\
Substancial & 23 & 52,3 \\
Muito grande & 9 & 20,4 \\
Total & 44 & 100,0 \\
\hline
\end{tabular}

TABELA 10: Motlvos que Levaram as Empresas a Abonarem a Opçăo de Desenvolver Sistema Próprlo

\begin{tabular}{lcc}
\hline Motivo & Freq. Abs. & $\%$ \\
\hline Tempo de desenvolvimento excessivamente longo & 23 & 74,2 \\
Insuficiente competência interna em informática & 9 & 29,0 \\
Custos superiores aos dos pacotes aplicativos & 11 & 35,5 \\
Outros & 4 & 12,9
\end{tabular}

Número de respondentes: 31 
metade das empresas.

A Tabela 13 permite afirmar que as empresas avaliaram bem a escolha (pacote aplicativo, sistema próprio ou ambos), pois a quase totalidade afirma estar satisfeita com a solução adotada. Cabe ressaltar, no entanto, que o maior percentual de empresas insatisfeitas ocorre entre as que optaram pela compra de um pacote aplicativo (uma entre cada 6). Mas o balanço global da implantação do sistema computadorizado foi considerado positivo por $94,3 \%$ das empresas, con- forme mostra a Tabela 14 .

Quanto à responsabilidade do projeto de informatização (independentemente da solução adotada), os resultados apresentados na Tabela 15 demonstram que, para a grande maioria das empresas $(85,7 \%)$, tal atividade foi desempenhada pela Direção Geral da organização $(24,5 \%)$ ou pelo responsável da área de informática $(29,6 \%)$, sendo que, para $31,6 \%$ dos casos, ocorreu uma combinação entre ambos. $\mathrm{O}$ alto índice de participação apresentado pela área

TABELA 11: Desenvolvimento de Sistema Próprio

\begin{tabular}{lrr}
\hline Sistema Desenvolvido por & Freq. Abs. & $\%$ \\
\hline Um grupo interno de informática & 43 & 69,3 \\
Por firma de consultoria & 6 & 9,7 \\
Ambos em cooperação & 13 & 21,0 \\
Total & 62 & 100,0 \\
\hline
\end{tabular}

TABELA 12: Motivos que Levaram as Empresas a Abandonarem a Possibilidade de Optar por Pacote Aplicativo

\begin{tabular}{lrr}
\hline Motivo & Freq. Abs. & $\%$ \\
\hline Custo excessivamente elevado & 12 & 30,0 \\
Equipamentos de computação não compatíveis & 6 & 15,0 \\
Inadequação às características de seu processo de produção & 33 & 82,5 \\
Difícil integração com os aplicativos já existentes na empresa & 20 & 50,0 \\
Número insuficiente de módulos de aplicação & 6 & 15,0 \\
Número excessivo de módulos de aplicação em relação às necessidades da empresa & 3 & 7,5 \\
Ausência de módulo de compras interessante & 5 & 12,5 \\
Ausência de um módulo de controle de materiais interessante & 5 & 12,5 \\
Ausência de um módulo de cálculo de custos de produção & 3 & 7,5 \\
\hline
\end{tabular}

Número de respondentes: 40

TABELA 13: Avaliaçấo da Soluçáo Adotada na Computadorizaçăo da Gestáo da Produçáo

\begin{tabular}{lccc}
\hline Solução Adotada & $\begin{array}{c}\text { Satisfeitas } \\
\text { Freq. Abs. }\end{array}$ & $\begin{array}{c}\text { Insatisfeitas } \\
\text { Freq. Abs. }\end{array}$ & $\begin{array}{c}\text { Percentual } \\
\text { Insatisfeitas }\end{array}$ \\
\hline Pacote aplicativo & 30 & 6 & 16,7 \\
Sistema próprio & 46 & 5 & 9,8 \\
Ambos & 10 & 1 & 9,1 \\
Total & 86 & 12 & 12,2 \\
\hline
\end{tabular}

TABELA 14: Balanço Global da Implantaçáo do SIstema Computadorizado de Gestáo da Produçáo

\begin{tabular}{lcc}
\hline Resultado & Freq. Abs. & $\%$ \\
\hline Positivo & 83 & 94,3 \\
Negativo & 5 & 5,7 \\
Total & 88 & 100,0 \\
\hline
\end{tabular}


de informática demonstra um padrão de comportamento que tende para o aspecto técnico da "ferramenta" utilizada, ou seja, o computador. O elevado índice de participação como responsável pelo projeto alcançado pela Direção Geral da empresa, por um lado, evidencia a importância que as empresas industriais brasileiras atribuem à implantação de sistemas computadorizados de gestão da produção. Por outro lado, tal atitude demonstra uma tendência centralizadora no comportamento das empresas, especialmente pelo baixo índice de participação das áreas de produção e materiais.

3.4. Motivos e Problemas Responsáveis pela Implantação de Recursos Computacionais

No sentido de identificar quais foram as razões de ordem mercadológica que mais influenciaram a decisão de utilizar recursos computacionais na gestão da produção, foram apresentados três possíveis motivos aos respondentes, obtendo-se os resultados apresentados na Tabela 16. A pressão exercida pela concorrência foi o motivo indicado por $86,2 \%$ dos respondentes, o que permite deduzir que a busca de maior competitividade teve fundamental participação na decisão de informatizar a gestão da produção.

Com relação a considerações técnicas ligadas à gestão da produção, procurou-se identificar a participação que alguns aspectos normalmente problemáticos à mesma tiveram quando da percepção da necessidade de sua informatização. Para tanto, formulou-se uma questão contendo esses aspectos, solicitando indicar o grau de importância que cada um deles tinha antes da implantação do sitema computadorizado, e o grau que este assumiu após a implantação. Utilizouse uma escala com um intervalo de valores inteiros de 0 a 4 , onde $o$ valor 0 indica que o aspecto considerado possui importância nula, e o valor 4; que o mesmo apresenta extrema importância.

A Tabela 17 apresenta a tabulação das médias obtidas para cada um dos aspectos problemáticos, antes e depois da implantação, além de uma informação complementar (na terceira coluna) indicando o percentual de empresas que apontaram o aspecto como relevante, isto é, com grau de importância superior a zero.

Examinando inicialmente a terceira coluna da Tabela 17, observa-se que, excetuando-se 0 estoque excessivo de produtos acabados $(59,7 \%)$ e o excesso de produtos defeituosos (50\%), todos os demais aspectos apresentados foram considerados de importância não nula por mais de $80 \%$ das empresas. Os aspectos que atingiram o maior grau como problema antes da implantação do sistema computadorizado são, pela ordem: o estoque excessivo de materiais, o atraso nos prazos.de entrega ao cliente, o ciclo de fabricação freqüentemente interrompido por falta de

\section{TABELA 15: Responsabllidade do Projeto de Informatizaçăo da Gestáo da Produçấo}

\begin{tabular}{lcc}
\hline Responsável & Freq. Abs. & $\%$ \\
\hline Direção geral & 24 & 24,5 \\
Responsável pela área de informática & 29 & 29,6 \\
Direção geral e responsável pela área de informática & 31 & 31,6 \\
Responsável pela área de produção & 3 & 3,1 \\
Responsável pela área de materiais & 9 & 9,2 \\
Consultores externos & 2 & 2,0 \\
& 98 & 100,0 \\
\hline
\end{tabular}

TABELA 16: Motlvos Mercadológicos que Conduzlram à Implantaçáo do SIstema Computadorlzado

\begin{tabular}{lrr}
\hline Motivos & Freq. Abs. & $\%$ \\
\hline Pressão exercida por clientes & 2 & 2,5 \\
Pressão exercida por fornecedores & 1 & 1,2 \\
Pressão exercida pela concorrência & 69 & 86,2 \\
Pressão exercida por clientes e pela concorrência & 4 & 5,0 \\
Pressão exercida por fornecedores e pela concorrência & 1 & 1,2 \\
Combinação de todos os motivos & 3 & 3,7 \\
Total & 80 & 100,0 \\
\hline
\end{tabular}


TABELA 17: Avallaçấo de Aspectos Problemáticos Referentes à Gestáo da Produçáo

\begin{tabular}{|c|c|c|c|}
\hline \multirow[b]{2}{*}{ Aspectos } & \multicolumn{2}{|c|}{ Grau de Importância } & \multirow{2}{*}{$\begin{array}{l}\text { Grau de Import. } \\
\text { Superior a Zero } \\
\text { (\% de Empresas) }\end{array}$} \\
\hline & $\begin{array}{l}\text { Antes da } \\
\text { Implantação }\end{array}$ & $\begin{array}{l}\text { Depois da } \\
\text { Implantação }\end{array}$ & \\
\hline Estoque excessivo de materiais & 2,9 & 1,8 & 94,6 \\
\hline Estoque excessivo de produtos em processo & 2,3 & 1,7 & 85,3 \\
\hline Estoque excessivo de produtos acabados & 1,4 & 1,0 & 59,7 \\
\hline Atraso nos prazos de entrega ao cliente & 2,8 & 1,9 & 89,7 \\
\hline Excesso de produtos defeituosos & 1,0 & 0,9 & 50,0 \\
\hline Custos de produção demasiadamente altos & 2,1 & 1,6 & 82,3 \\
\hline Ciclo de fabricação demasiadamente longo & 2,2 & 1,6 & 82,3 \\
\hline $\begin{array}{l}\text { Ciclo de fabricação freqüentemente interrompido } \\
\text { por falta de materiais ou componentes }\end{array}$ & 2,6 & 1,8 & 86,1 \\
\hline $\begin{array}{l}\text { Insuficiente flexibilidade na utilização da capaci- } \\
\text { dade de produção }\end{array}$ & 2,0 & 1,6 & 80,9 \\
\hline
\end{tabular}

materiais ou componentes e o estoque excessivo de produtos em processo. Todos esses aspectos foram considerados de importância não nula por mais de $85 \%$ das empresas, o que evidencia que existe similaridade nos problemas enfrentados pelas empresas industriais brasileiras dos setores pesquisados. Estes problemas referem-se, resumidamente, ao planejamento das necessidades de materiais e serviço ao cliente.

Os dados da Tabela 17 mostram que, após a implantação do sistema computadorizado, houve melhoria em todos os aspectos considerados. $O$ estoque excessivo de materiais, problema apontado como sendo de importância não nula por $94,6 \%$ das empresas respondentes, foi o que teve um índice de melhoria mais significativo. As dificuldades apresentadas pelo atraso nos prazos de entrega ao cliente e o ciclo de fabricação freqüentemente interrompido por falta de materiais ou componentes foram aspectos que tiveram também, pela ordem, destaque na melhoria de seu comportamento.

$\mathrm{O}$ aspecto que menos apresentou melhoria após a implantação do sistema computadorizado foi o excesso de produtos defeituosos, o qual também foi o que teve, na média, menor grau de importância bem como a maior representatividade como sendo de importância nula pelas empresas consultadas (50\%).

\subsection{Abrangência da Informatização do Sistema de Gestão da Produção \\ Um sistema de gestão da produção é compos- to por um conjunto de subsistemas, cada qual desempenhando uma função específica dentro das várias atribuições e atividades desenvolvi- das por esse sistema. Desta forma, quando refe- renciamos "informatização do sistema de gestão da produção", tem-se apenas a noção de que estão sendo utilizados recursos de processamen-}

to eletrônico de dados na gestão do sistema. Essa noção necessita ser desenvolvida de forma a obter-se uma idéia clara de quais elementos da gestão da produção estão efetivamente informatizados.

A Tabela 18 apresenta os possíveis elementos (subsistemas) componentes de um sistema de gestão da produção, identificando, para as empresas consideradas informatizadas $(64 \%$ da amostra), o percentual de empresas em que esses elementos estão computadorizados. A maioria destes elementos apresenta uma parcela significativa de computadorização, destacando-se principalmente o inventário de estoque de matérias-primas e semi-elaborados, lista de materiais, inventário de estoque de produtos acabados e planejamento das necessidades de materiais, com índices superiores a $70 \%$. Os elementos com índices de computadorização abaixo de $50 \%$ são a programação das operações (microprogramação) e previsão de vendas.

$\mathrm{O}$ alto índice de computadorização registrado nos subsistemas de estoque de matérias-primas e semi-elaborados $(92,9 \%)$, inventário de estoque de produtos acabados $(80,2 \%)$ e planejamento das necessidades de materiais $(72,5 \%)$ vem atender a um dos principais problemas enfrentados pelas empresas brasileiras, conforme identificado anteriormente, qual seja, o planejamento e controle de materiais. A partir de uma melhor realização do planejamento das necessidades de materiais, através da lista de materiais de cada produto, aliada a um eficiente sistema de inventário, o nível de serviço ao cliente deverá elevar-se, evitando-se a interrupção no ciclo de produção causada pela não disponibilidade de materiais e componentes e, conseqüentemente, atrasos nos prazos de entrega ao cliente. Desta forma, explicam-se os índices significativos de melhoria apresentados para 
TABELA 18: Subsistemas da Gestáo da Produçáo - Proporçáo de Empresas Computadorizadas

\begin{tabular}{lc}
\hline Subsistemas & Percentual** \\
\hline Previsão de vendas & 42,0 \\
Lista de materiais (estrutura dos produtos) & 88,7 \\
Inventário de estoque de matérias-primas e semi-elaborados & 92,9 \\
Inventário de estoque de produtos acabados & 80,2 \\
Plano mestre da produção & 55,6 \\
Planejamento das necessidades de materiais (explosão do produto final em partes) & 72,5 \\
Liberação (emissão) de ordens de produção & 53,8 \\
Compras & 62,4 \\
Planejamento das necessidades de capacidade de produção & 62,0 \\
Programação das operaçōes (microprogramação) & 33,7 \\
Acompanhamento, monitorização e controle da produção & 52,7 \\
\hline
\end{tabular}

${ }^{*}$ Refere-se somente às empresas consideradas informatizadas ( $64 \%$ das empresas na amostra).

TABELA 19: Grau de Confiabilidade (Acuracidade) das Informaçoes

\begin{tabular}{lc}
\hline Subsistemas & Grau \\
\hline Previsão de vendas & 2,5 \\
Lista de materiais (estrutura dos produtos) & 3,3 \\
Estoque de materiais & 3,3 \\
Estoque de semi-elaborados & 3,0 \\
Plano mestre da produção & 2,9 \\
Prazo de entrega do fornecedor & 2,6 \\
Tempo de fabricação (lead-time) & 2,7 \\
Acompanhamento, monitorização e controle da produção & 3,1 \\
Planejamento das necessidades de capacidade de produção & 2,8
\end{tabular}

esses problemas (Tabela 17) após a implantação de recursos de processamento eletrônico de dados.

Objetivando inferir o nível de confiabilidade (acuracidade) das informações geradas pela informatização do sistema de gestão da produção, formulou-se uma questão contendo alguns dos principais elementos componentes da função, solicitando indicar o grau de confiabilidade das informações nos mesmos. Para tanto, utilizouse uma escala com um intervalo de valores inteiros de 1 a 4 , onde o valor 1 indica que as informações geradas são de baixa confiabilidade $e$ o valor 4, que as mesmas são de alta confiabilidade.

As médias obtidas estão apresentadas na Tabela 19 , onde se observa que a média mais baixa é de 2,5 (previsão de vendas) e a mais alta, de 3,3 (lista de materiais e estoque de materiais), o que permite afirmar que, de modo geral, o grau de acuracidade das informações geradas pelos diferentes elementos do sistema de gestão da produção pode ser considerado satisfatório, embora ainda muito aquém do que se poderia esperar desses subsistemas.

O maior grau de acuracidade das informações referentes aos estoques e lista de materiais vem ao encontro dos esforços de melhoria de desem- penho realizados pelas empresas ao computadorizarem os subsistemas relacionados aos inventários de estoque e ao planejamento das necessidades de materiais.

No intuito de inferir a abrangência da informatização do sistema de gestão da produção, formulou-se uma questão visando a identificar se o sistema computadorizado existente, em desenvolvimento ou previsto, envolve todos os aspectos da produção. Os resultados indicam que metade das empresas tem pelo menos prevista a implantação de um sistema computadorizado envolvendo todos os aspectos da produção. Os dados obtidos em complemento a essa questão, contemplando as empresas que não se enquadraram no grupo acima referenciado, permitem afirmar que $80 \%$ das empresas respondentes pretendem difundi-los em todos os setores da produção. Apenas $20 \%$ das empresas respondentes não possuem tal objetivo, 0 que demonstra uma alta tendência de informatização de todos os aspectos e subsistemas componentes dos sistemas de gestão da produção das grandes empresas brasileiras dos setores pesquisados.

\subsection{Recursos Computacionais Utilizados}

Foram identificados, inicialmente, os recur- 
sos a nível de configuração de hardware e modalidade de processamento utilizado no sistema de informaçãoo referente à gestão da produção. Através da Tabela 20, constata-se que a utilização de um computador central em modo online foi a solução mais adotada pelas empresas informatizadas com um percentual de $28,1 \%$, sendo a segunda solução mais adotada uma aplicação mista utilizando o modo batch/on-line, com $24,4 \%$ dos casos. É importante destacar que o uso de microcomputadores como terminais inteligentes (linhas 5 e 6 da tabela), complementa as duas soluções, as quais passam a atingir percentuais de $31,7 \%$ e $30,5 \%$ respectivamente. De modo geral, tal solução explica-se pela complexidade exigida de um sistema de informação que abranja os vários subsistemas que compõem o sistema de gestão da produção (identificados anteriormente na Tabela 18), sendo o uso das facilidades on-line fundamentais a tal aplicação.

Com relação à manipulação (entrada e saída de informações através de terminais direta- mente dos locais onde se fazem necessárias, observa-se, na Tabela 21, que os setores mais diretamente envolvidos com os aspectos específicos do sistema de gestão da produção (almoxarifado, compras, fábrica e engenharia de produto) apresentam percentuais acima de $60 \%$ na utilização de tal capacidade.

$\mathrm{Na}$ Tabela 22 , verifica-se a capacidade de alimentação do sistema de informação diretamente dos postos de trabalho. Observa-se que somente $17,5 \%$ das empresas informatizadas não estão habilitadas à realização de tal tarefa, sendo que um índice significativo dessas empresas $(31,2 \%)$ declara-se capaz de sua execução para todos os postos de trabalho. Tal informação revela o alto grau de potencialidade dos recursos disponíveis nas empresas dos setores consultados.

\subsection{CAD, CAE, CAM, FMS}

Entre os modernos recursos disponíveis para utilização dos setores produtivos, encontram-se os aplicativos de CAD (Desenho Assistido por

TABELA 20: Estrutura Computacional Utilizada

\begin{tabular}{lrr}
\hline Estrutura & Freq. Abs. & $\%$ \\
\hline 1. Computador central em Modo Batch & 10 & 12,2 \\
2. Computador central em Modo On-Line & 23 & 28,1 \\
3. Computador central em Modo Batch/On-Line & 20 & 24,4 \\
4. Microcomputadores autônomos & 1 & 1,2 \\
5. Computador central em Modo On-Line com conexäo de microcomputadores & 3,6 \\
6. Computador central em Modo Batch/On-Line com conexāo de microcomputadores & 5 & 6,1 \\
7. Computador central em Modo Batch e microcomputadores autônomos & 4,9 \\
8. Computador central em Modo On-Line e microcomputadores autônomos & 4,9 \\
9. Computador central em Modo Batch/On-Line e microcomputadores autônomos & 4 & 9 \\
10. Computador central em Modo Batch/On-Line e microcomputadores organizados em rede & 3 & 3,6 \\
Total & 82 & 100,0 \\
\hline
\end{tabular}

TABELA 21: Manipulaçáo de Informaçðes - Setores Capacitados

\begin{tabular}{lcc}
\hline Setor & Freq. Abs. & $\%$ \\
\hline Almoxarifado & 64 & 80,0 \\
Fábrica & 53 & 66,2 \\
Marketing & 17 & 21,2 \\
Organização e métodos & 17 & 21,2 \\
Vendas & 41 & 51,2 \\
Direçāo geral & 19 & 23,7 \\
P\&D & 19 & 23,7 \\
Finanças & 41 & 51,2 \\
Compras & 60 & 75,0 \\
Engenharia de produtos & 50 & 62,5 \\
Outros & 25 & 31,2 \\
\hline
\end{tabular}

Número de respondentes: 80 
TABELA 22: Acesso ao SIstema Diretamente dos Postos de Trabaiho

\begin{tabular}{lcr}
\hline Capacidade & Freq. Abs. & $\%$ \\
\hline Para todos os postos & 25 & 31,2 \\
Para maioria & 26 & 32,5 \\
Alguns & 15 & 18,7 \\
Nenhum & 14 & 17,5 \\
Total & 80 & 100,0 \\
\hline
\end{tabular}

Computador), CAE (Engenharia Assistida por Computador) e CAM (Fabricação Assistida por Computador). Os dados obtidos na pesquisa, apresentados na Tabela 23, demonstram que o aplicativo mais utilizado pelas empresas de grande porte dos setores componentes da pesquisa é o CAE $(11,6 \%)$, seguido de perto pelo CAD $(9,6 \%)$, sendo inexpressivo o percentual referente ao CAM. Existe, porém, um percentual significativo de empresas em que os mesmos se encontram em fase de desenvolvimento e implantação. Somados tais percentuais, obtêm-se $24,7 \%$ para o CAD, $23,2 \%$ para o CAE e $17,1 \%$ para o CAM.

Percebe-se, com esses resultados, que ainda é pequena a iniciativa das empresas brasileiras no sentido da utilização desses recursos. É necessário, porém, considerar o tipo de processo de produção e sua complexidade, na interpretação desses resultados, pois o uso de tais aplicativos pode não ser necessário para todos os tipos de empresas componentes da amostra. Considerando-se, ainda, os percentuais referentes às empresas em que está prevista a utilização de tais recursos, é possível afirmar que a maioria das grandes empresas industriais brasileiras deverá ser usuária desses aplicativos futuramente.

Uma das formas mais modernas de aplicação dos recursos fornecidos pela informática no processo produtivo é a utilização de Sistema Flexível de Manufatura - FMS (conjunto de equipamentos comandados integralmente por computador). Conforme se verifica na Tabela 24 , a utilização de FMS restringe-se a apenas $2 \%$ - das empresas. $O$ percentual de empresas que estão implantando esse tipo de sistema $(13,9 \%)$ e o que prevê a sua utilização até $1988(25,8 \%)$ permitem afirmar que as grandes empresas industriais brasileiras vêm incorporando os novos desenvolvimentos tecnológicos aos seus processos produtivos em um ritmo bastante acelerado.

\subsection{A Meta "Estoque Zero"}

As modernas técnicas de gestão da produção enfatizam como aspecto básico a necessidade de aplicação do conceito de "estoque zero". Visando a chegar-se a conclusóes referentes a este tema, questionaram-se as empresas quanto à iniciativa de desenvolver ações que busquem atingir estoque zero. Apenas $26,5 \%$ das empresas respondentes declararam perseguir tal obje-

TABELA 23: Utillzaçăo de Aplicativos

\begin{tabular}{|c|c|c|c|c|c|c|}
\hline \multirow[t]{2}{*}{ Aplicativo } & \multicolumn{2}{|c|}{ Em Utilização } & \multicolumn{2}{|c|}{ Em Desenvolvimento } & \multicolumn{2}{|c|}{ Previsto } \\
\hline & FA & $\%$ & FA & $\%$ & FA & $\%$ \\
\hline CAD & 14 & 9,6 & 22 & 15,1 & 51 & 35,0 \\
\hline CAE & 17 & 11,6 & 17 & 11,6 & 49 & 33,6 \\
\hline CAM & 6 & 4,1 & 19 & 13,0 & 58 & 39,7 \\
\hline
\end{tabular}

Número de respondentes: 146

TABELA 24: Utillzaçăo de Sistema Flexivei de Manufatura (FMS)

\begin{tabular}{lcr}
\hline Situação & Freq. Abs. & $\%$ \\
\hline Em utilização & 3 & 2,0 \\
Em desenvolvimento & 21 & 13,9 \\
Previsto & 39 & 25,8 \\
Não previsto & 88 & 58,3 \\
Total & 151 & 100,0 \\
\hline
\end{tabular}


tivo. Os motivos pelos quais as demais $73,5 \%$ das empresas não pretendem atingir essa meta estão apresentados na Tabela 25.

Observa-se que os dois motivos apontados se relacionam ao problema de instabilidade de comportamento na demanda de produtos $(58 \%)$ e aos prazos de entrega dos fornecedores $(53,8 \%)$. Estas duas principais restrições apontadas vêm de encontro a qualquer tentativa de aproximarse do estoque zero. Quanto maior a variabilidade nos prazos de entrega dos fornecedores, maiores serão os níveis de estoques de segurança de matérias-primas e componentes que a empresa deverá manter para assegurar um determinado ritmo de produção. Se, além disso, ainda houver instabilidade no comportamento da demanda, qualquer tentativa de introduzir a filosofia JIT (just-in-time) ou KANBAN estará fadada ao fracasso.

Tomando-se o grupo de $26,2 \%$ de empresas que consideraram desenvolver ações que visem a atingir estoque zero, inquiriu-se sobre a compatibilidade do sistema KANBAN com o atual sistema de gestão da produção, no intuito de verificar a possibilidade de implantação deste nestas empresas. Os resultados apresentados na Tabela 26 indicam que $60,5 \%$ dessas empresas somente poderiam implantar KANBAN após a reorganização do processo de fabricação, de modo a adequá-lo às características desse tipo de sistema. Apenas $4,7 \%$ das empresas compo- nentes desse grupo ( $1,2 \%$ da amostra) poderiam implantá-1o no estado atual do sistema de gestão e $9,4 \%$ (2,4\% da amostra) declararam já serem usuárias de KANBAN.

Sistemas tipo MRP - Material Requirements Planning (Planejamento das Necessidades de Materiais) já possuem uma representatividade de usuários bem mais expressiva do que o sistema KANBAN, uma vez que $28 \%$ das empresas componentes da amostra se declararam usuárias deste tipo de sistema de planejamento de necessidades de materiais ${ }^{(4)}$. Esse percentual de empresas servirá de base para uma análise posterior que enfocará os vários aspectos relacionados à implantação e utilização dos sistemas MRP, bem como a avaliação do desempenho desses sistemas nas empresas usuárias.

Informações adicionais quanto à utilização de sistemas do tipo MRP demonstraram que existe um expressivo número de empresas $(36,5 \%)$ que pretendem implantar este tipo de sistema. Por outro lado, constatou-se que $41,2 \%$ das empresas componentes da amostra declararam não conhecer o sistema MRP, o que, de certa forma, é um resultado surpreendente, uma vez que esse tipo de sistema vem sendo utiliza-

4. É provável que o número de empresas que utilizam os princípios básicos do sistema MRP seja superior aos $28 \%$ de empresas que explicitamente declararam utilizar este tipo de sistema.

\section{TABELA 25: Restriç̧es à Apllcaçáo do Concelto de Estoque Zero}

\begin{tabular}{lcc}
\hline Tipos de Restriçōes & Freq. Abs. & $\%$ \\
\hline Demanda dos produtos demasiadamente aleatória & 69 & 58,0 \\
Qualidade dos componentes causa sérios problemas & 21 & 17,6 \\
Prazos de entrega dos fornecedores demasiadamente longos & 44 & 37,0 \\
Prazos de entrega dos fornecedores demasiadamente variáveis & 64 & 53,8 \\
Tempos de preparação dos equipamentos e ferramental demasiadamente longos & 24 & 20,2 \\
Produção não organizável em fluxo contínuo & 56 & 47,0 \\
\hline
\end{tabular}

Número de respondentes: 119

\section{TABELA 26: Utilizaçăo de SIstema KANBAN}

\begin{tabular}{lcc}
\hline Capacitação para Implantação de. KANBAN & Freq. Abs. & $\%$ \\
\hline Após a reorganização do processo de fabricação & 26 & 60,5 \\
Quando desenvolvimentos futuros forem realizados & 13 & 30,2 \\
Não possui conhecimento suficiente sobre o sistema KANBAN & 5 & 11,6 \\
No estado atual do sistema de gestāo & 2 & 4,7 \\
Já utiliza o sistema KANBAN & 4 & 9,3 \\
\hline
\end{tabular}

Número de respondentes: 43 
do desde a década de setenta nos países desenvolvidos, sendo amplo o debate em torno de sua utilização.

\section{CONCLUSÕES}

A análise dos resultados obtidos na pesquisa mostra um quadro animador quanto às inovações tecnológicas na gestão da produção, especificamente quanto à utilização do processamento eletrônico de dados como ferramenta na geração e atualização de informações. Esse fato, ao nosso ver, é indispensável às organizações empresariais brasileiras que pretendem aumentar a produtividade através da utilização adequada de recursos materiais e humanos.

A ciência da administração utiliza-se de duas palavras básicas: planejamento e controle. Muitos modelos e técnicas têm sido desenvolvidos no mundo inteiro, no sentido de permitir um planejamento e controle da produção mais qualificados e eficazes. O desenvolvimento e a aplicação da maioria dessas técnicas só foi possível utilizando-se dos recursos e facilidades oferecidas pelo computador. Sistemas complexos como MRP II - Manufacturing Resources Planning (Planejamento dos Recursos de Manufatura), cuja necessidade de informações e processamento das mesmas é enorme, só são passíveis de aplicação com sucesso tendo toda uma estrutura de suporte, sendo o recurso fundamental o computador. A tendência demonstrada pelas empresas industriais brasileiras de informatizarem seus sistemas de gestão da produção não representa, portanto, nada mais do que 0 indispensável para o seu desenvolvimento.

O processo de implantação de sistemas computadorizados na maioria das empresas está ocorrendo paulatinamente e, de acordo com os dados pesquisados, as soluções oferecidas têm sido satisfatórias, atingindo as expectativas globais de seus usuários. Nota-se que efeitos mercadológicos da pressão da concorrência têm contribuído para a tomada desta decisão; a concorrência leva as empresas a se aprimorarem continuamente nas aplicações permitidas pela utilização do computador.

Os problemas identificados como comuns à maioria das grandes empresas industriais brasileiras referem-se, de modo geral, ao planejamento das necessidades de materiais, passando pelo sistema de inventário de estoques e refletindo-se no nível de serviço ao cliente. Tais problemas estão sendo tratados diretamente pela informatização do sistema de gestão da produção, sendo animadores os resultados obtidos pelas soluções apresentadas, elevando a confia- bilidade das informações geradas para atender às necessidades específicas dos subsistemas de gestão da produção diretamente relacionados a esses aspectos.

Observa-se uma razoável disponibilidade de recursos computacionais nas empresas consultadas, sendo que, a nível estrutural, estes estão, em sua grande maioria, definidos de acordo com os padrões de centralização no centro de processamento de dados. A utilização de aplicativos do tipo CAD, CAE e CAM começa a ser difundida, indicando perspectivas futuras de crescimento no número de usuários. O mesmo pode ser dito quanto à utilização de Sistema Flexível de Manufatura (FMS).

Os resultados da pesquisa demonstram que as empresas brasileiras começam a implantar sistemas de gestão do tipo KANBAN e MRP, sendo pequeno o número de usuários do primeiro ( $2,4 \%$ da amostra) em relação ao segundo (28\% da amostra). As perspectivas de utilização de sistemas do tipo MRP apresentam-se altamente promissoras, o que define a preocupação do empresariado brasileiro em utilizar os recursos mais modernos disponíveis para o planejamento e controle da produção.

Os resultados globais apresentados na pesquisa e avaliados neste artigo permitem concluir que o crescimento e amadurecimento a nível de informatização do sistema de gestão da produção nas grandes empresas industriais brasileiras encontra-se em franca expansão, na medida em que existe uma percepção clara por parte do empresário brasileiro sobre os benefícios passíveis de serem atingidos com o uso do computador como ferramenta geradora de informações.

Cabe observar, no entanto, que a informatização por si só não constitui uma solução aos problemas da gestão da produção, como nos demonstram as experiências americanas e japonesas. Enquanto os americanos têm buscado (sobretudo na década de setenta) ganhos de eficiência através do desenvolvimento de sistemas computadorizados altamente complexos para gerenciar a crescente complexidade de seus sistemas produtivos, os japoneses dedicaram-se a atacar as causas da complexidade, simplificando seus sistemas produtivos a ponto de poderem gerir manualmente certos subsistemas da produção com apenas um punhado de cartões KANBAN. Ganhos de eficiência através de ações que visem à redução da complexidade do sistema produtivo devem, portanto, preceder a decisão de informatização, sob pena de incorrerse no erro, geralmente caro, de informatizar a ineficiência. 